\title{
Emerging biomarkers for neoadjuvant immune checkpoint inhibitors in operable non-small cell lung cancer
}

\author{
Monika Pradhan ${ }^{1}$, Mathieu Chocry ${ }^{2}$, Don L. Gibbons ${ }^{1,3}$, Boris Sepesi ${ }^{4}$, Tina Cascone ${ }^{1}$ \\ ${ }^{1}$ Department of Thoracic/Head and Neck Medical Oncology, The University of Texas MD Anderson Cancer Center, Houston, TX, USA; ${ }^{2}$ Aix- \\ Marseille Université, Institut de Neurophysiopathologie (INP), CNRS, Marseille, France; ${ }^{3}$ Department of Molecular and Cellular Oncology, The \\ University of Texas MD Anderson Cancer Center, Houston, TX, USA; ${ }^{4}$ Department of Thoracic and Cardiovascular Surgery, The University of \\ Texas MD Anderson Cancer Center, Houston, TX, USA \\ Contributions: (I) Conception and design: M Pradhan, T Cascone; (II) Administrative support: T Cascone; (III) Provision of study materials \\ or patients: B Sepesi, T Cascone; (IV) Collection and assembly of data: M Pradhan, M Chocry, B Sepesi, T Cascone; (V) Data analysis and \\ interpretation: M Pradhan, M Chocry, B Sepesi, T Cascone; (VI) Manuscript writing: All authors; (VII) Final approval of manuscript: All authors. \\ Correspondence to: Tina Cascone, MD, PhD. Department of Thoracic/Head and Neck Medical Oncology, The University of Texas MD Anderson \\ Cancer Center; 1515 Holcombe Blvd, Unit 432, Houston, TX 77030, USA. Email: tcascone@mdanderson.org.
}

\begin{abstract}
The advent of immune checkpoint inhibitors (ICIs) has dramatically changed the treatment of patients with locally advanced unresectable and metastatic non-small cell lung cancer (NSCLC). Now, ICIs are undergoing evaluation as neoadjuvant therapy in patients with early-stage, resectable NSCLC using candidate surrogate endpoints of clinical efficacy, i.e., major pathologic response (MPR, $\leq 10 \%$ viable tumor cells in resected tumors). The initial results from early, small-scale trials are encouraging; however, they also reveal that a substantial number of patients with operable disease may not benefit from neoadjuvant ICIs. Consequently, much investigative effort is currently directed toward identifying mechanisms of resistance to ICI therapy in resectable NSCLC. There is also an urgent need for biomarkers that could be used to guide the clinical decision-making process and maximize the clinical benefit of ICIs in patients with early-stage, resectable NSCLC. Here, we summarize the initial results from the trials of neoadjuvant ICIs in patients with early-stage and locally advanced operable NSCLC and review the findings of studies investigating emerging biomarkers associated with those trials.
\end{abstract}

Keywords: Early-stage non-small cell lung cancer (early-stage NSCLC); biomarkers; neoadjuvant immune checkpoint inhibitors

Submitted Apr 18, 2020. Accepted for publication Sep 18, 2020.

doi: $10.21037 /$ tlcr-20-573

View this article at: http://dx.doi.org/10.21037/tlcr-20-573

\section{Introduction}

Non-small cell lung cancer (NSCLC) represents approximately $85 \%$ of all newly diagnosed cases of lung cancer (1). Among them, approximately $20 \%$ of cases are characterized as localized disease (stage I and II), 25\% as locally advanced disease (stage III), and $55 \%$ of cases are metastatic disease (stage IV) (2). Surgical resection is the preferred treatment option for patients with earlystage and some locally advanced NSCLC; however, more than $50 \%$ of patients who are treated with surgery alone will develop local or distant recurrence (3). Introduction of chemotherapy before (neoadjuvant) or after (adjuvant) surgery provides an absolute improvement of approximately $5 \%$ in 5-year overall survival (OS) (4-6) and is a source of considerable toxicity. Consequently, there is an urgent need to implement new therapeutic strategies for patients with operable NSCLC. While advances in the development of new perioperative treatments for patients with resectable NSCLC have lagged behind, the treatment of patients with advanced/metastatic NSCLC has changed dramatically over recent years. Treatment plans are now informed by 
extensive molecular testing and many patients receive treatment with small molecule inhibitors that target somatic genomic aberrations (7), which have been shown to provide a survival benefit for some patients (8).

Antibodies directed against the immune checkpoint proteins programmed cell death $1(\mathrm{PD}-1)$ protein and its ligand (PD-L1), lead to the activation of cytotoxic $\mathrm{T}$ cell effector function and have been shown to be an effective treatment approach for a subset of patients with unresectable locally advanced, and metastatic NSCLC (9). Immune checkpoint inhibitors (ICIs) are also less toxic than chemotherapy and may impart immunologic memory, and thus provide durable clinical benefit (10). Given their success in the locally advanced unresectable and metastatic disease settings, it is not surprising that ICIs are now being evaluated as neoadjuvant therapy for patients with operable NSCLC.

The administration of ICIs in the neoadjuvant setting offers several theoretical advantages. For example, because patients with early-stage disease are at risk of relapse after surgery, neoadjuvant ICIs could prime the antitumor immune response at an early time point, eradicate micrometastatic disease, and prevent tumor relapse. Neoadjuvant treatment also provides an opportunity for early assessment of tumor response to therapy using candidate surrogate endpoints of clinical efficacy at surgery that can correlate with disease-free survival (DFS) and OS. Furthermore, neoadjuvant treatment may prove beneficial because early-stage lung cancers may possess higher clonal neoantigen burden which has been shown to correlate with improved survival as compared to that of patients with more heterogeneous (subclonal) neoantigens within their tumor (11).

The development of new perioperative treatment strategies for resectable NSCLC was hindered by a lack of surrogate endpoints of clinical efficacy. However, retrospective and, more recently, small-scale early-phase prospective studies have shown that major pathologic response (MPR), defined as $10 \%$ or less viable tumor in resected tumor specimens at surgery, is associated with long-term survival in patients with NSCLC treated with neoadjuvant chemotherapy (12-15). MPR was previously defined following neoadjuvant chemotherapy (12), and the utility of MPR as a candidate surrogate endpoint to rapidly evaluate the clinical efficacy of neoadjuvant ICIs remains unclear. Currently, there are several phase II and III clinical trials underway examining neoadjuvant ICI-based treatments in patients with operable NSCLC that are using MPR as a surrogate endpoint of efficacy (Tables 1 and 2).
Early studies investigating neoadjuvant ICIs have reported MPR rates ranging between $17 \%$ and $45 \%$ (16-21). In the first feasibility study (NCT02259621), two doses of neoadjuvant nivolumab (anti-PD-1 antibody) induced a $45 \%$ MPR rate in 20 resected patients with NSCLC with no major delays in surgery (16). Three patients achieved pathologic complete response (pCR; $0 \%$ viable tumor cells), however, in one of them, residual tumor was seen in hilar lymph nodes (16). In the multicenter Lung Cancer Mutation Consortium (LCMC3) study (NCT02927301), two cycles of neoadjuvant atezolizumab (anti-PD-L1 antibody) induced a 19\% MPR rate and 5\% of evaluable patients achieved a pCR (17). In a neoadjuvant study evaluating the PD-1 inhibitor sintilimab (antiPD-1 antibody) in 37 Chinese patients with resectable NSCLC, two doses of neoadjuvant therapy induced an MPR rate of $40.5 \%$ in patients, including $16.2 \%$ with pCR in the primary tumor and $8.1 \%$ in the lymph nodes (21). Initial results from the first phase II randomized, singleinstitution study, NEOSTAR (NCT03158129), which tested neoadjuvant nivolumab as single agent or combined with ipilimumab (anti-cytotoxic T-lymphocyte-associated protein 4 [CTLA-4] antibody) in 44 patients with resectable NSCLC, revealed that three doses of nivolumab monotherapy produced a $17 \%$ MPR rate, including a $9 \%$ pCR rate, whereas combination therapy induced a $33 \%$ MPR rate, including a $29 \%$ pCR rate, in the intention-totreat patient population (18). ICIs are now being tested in combination with platinum doublet chemotherapy in patients with resectable NSCLC and early results have demonstrated MPR rates ranging between $57 \%$ and $83 \%$ following chemotherapy plus PD-1/PDL- 1 inhibition, and pCR rates reported between $33 \%$ and $63 \%$ in two studies $(22,23)$.

While the initial results from clinical testing of ICIs in patients with resectable NSCLC are encouraging, responses to neoadjuvant ICI therapies are not uniform and many tumors are refractory to treatment for reasons that are poorly understood. Therefore, there is an urgent need to identify biomarkers of response to neoadjuvant ICIs in order to maximize clinical benefit. Biomarkers will optimize selection of patients for the most appropriate therapy, mitigate unnecessary toxicities and risks, and reduce healthcare costs. In the sections below, we summarized current studies evaluating neoadjuvant ICIs for patients with resectable NSCLC and discussed emerging biomarkers (Figure 1) under investigation for neoadjuvant immunebased therapies in these patients. 
Table 1 Select phase I-II clinical trials investigating neoadjuvant immune checkpoint inhibitor/s in patients with operable NSCLC

\begin{tabular}{|c|c|c|c|c|c|c|}
\hline $\begin{array}{l}\text { Trial name (Registry } \\
\text { number) clinicaltrials. } \\
\text { gov }\end{array}$ & $\begin{array}{l}\text { NSCLC } \\
\text { stage }\end{array}$ & $\begin{array}{l}\text { Estimated } \\
\text { enrollment }\end{array}$ & Neoadjuvant arm & Adjuvant arm & Primary endpoint & Phase \\
\hline NCT02259621 & IB-IIIA & $\mathrm{N}=30$ & Nivolumab +/- Ipilimumab & SoC & $\begin{array}{l}\text { Safety and } \\
\text { Feasibility }\end{array}$ & II \\
\hline \multirow{3}{*}{$\begin{array}{l}\text { NEOSTAR } \\
\text { (NCT03158129) }\end{array}$} & \multirow[t]{3}{*}{$\mathrm{I}-\mathrm{IIIA}$} & \multirow[t]{3}{*}{$\mathrm{N}=88$} & Arm A: Nivolumab & Arm A: SoC & \multirow[t]{3}{*}{ MPR } & \multirow[t]{3}{*}{ II } \\
\hline & & & Arm B: Nivolumab+ Ipilimumab & Arm B: SoC & & \\
\hline & & & $\begin{array}{l}\text { Arm C: Nivolumab + Platinum } \\
\text { doublet CT }\end{array}$ & Arm C: SoC & & \\
\hline $\begin{array}{l}\text { NADIM } \\
\text { (NCT03081689) }\end{array}$ & IIIA-N2 & $\mathrm{N}=46$ & $\begin{array}{l}\text { Nivolumab + Carboplatin + } \\
\text { Paclitaxel }\end{array}$ & Nivolumab & 24-month PFS & II \\
\hline $\begin{array}{l}\text { NADIM II } \\
\text { (NCT03838159) }\end{array}$ & IIIA/IIIB & $\mathrm{N}=90$ & $\begin{array}{l}\text { Nivolumab + Carboplatin + } \\
\text { Paclitaxel }\end{array}$ & Nivolumab & $\mathrm{pCR}$ & ॥ \\
\hline & & & Carboplatin + Paclitaxel & & & \\
\hline NCT02716038 & IB-IIIA & $\mathrm{N}=30$ & $\begin{array}{l}\text { Atezolizumab + carboplatin }+ \\
\text { Nab-paclitaxel }\end{array}$ & SoC & MPR & ॥ \\
\hline $\begin{array}{l}\text { NEOCOAST } \\
(\text { NCT03794544) }\end{array}$ & $\mathrm{I}-\mathrm{IIIA}$ & $N=160$ & Arm A: Durvalumab & Arm A: SoC & MPR & ॥ \\
\hline $\begin{array}{l}\text { SAKK 16/14 } \\
\text { (NCT02572843) }\end{array}$ & IIIA & $\mathrm{N}=68$ & Chemotherapy + Durvalumab & Durvalumab +/- RT & EFS & $\|$ \\
\hline $\begin{array}{l}\text { NEOMUN } \\
\text { (NCT03197467) }\end{array}$ & $\|-\| I A$ & $\mathrm{~N}=30$ & Pembrolizumab & SoC & $\begin{array}{l}\text { Feasibility, } \\
\text { safety, clinical } \\
\text { and pathologic } \\
\text { responses }\end{array}$ & $\|$ \\
\hline NCT03237377 & IIIA & $\mathrm{N}=32$ & $\begin{array}{l}\text { Durvalumab + RT } \\
\text { Durvalumab + Tremelimumab + } \\
\text { RT }\end{array}$ & $\begin{array}{l}\text { SoC } \\
\text { SoC }\end{array}$ & $\begin{array}{l}\text { Toxicities, } \\
\text { Feasibility of } \\
\text { Preoperative } \\
\text { ImmunoRT }\end{array}$ & II \\
\hline NCT02904954 & I-IIIA & $\mathrm{N}=60$ & $\begin{array}{l}\text { Arm 1: Durvalumab } \\
\text { Arm 2: Durvalumab + SBRT }\end{array}$ & $\begin{array}{l}\text { Arm 1: Durvalumab } \\
\text { Arm 2: Durvalumab }\end{array}$ & DFS & $\|$ \\
\hline
\end{tabular}

Table 1 (Continued) 
Table 1 (Continued)

\begin{tabular}{lccccc}
\hline $\begin{array}{l}\text { Trial name (Registry } \\
\text { number) clinicaltrials. } \\
\text { gov }\end{array}$ & $\begin{array}{c}\text { NSCLC } \\
\text { stage }\end{array}$ & $\begin{array}{c}\text { Estimated } \\
\text { enrollment }\end{array}$ & Neoadjuvant arm & Adjuvant arm & Primary endpoint \\
\hline $\begin{array}{l}\text { PRICNEPS } \\
\text { (NCT02994576) }\end{array}$ & $\begin{array}{c}\text { IA-IIIA } \\
\text { (no N2) }\end{array}$ & $\mathrm{N}=60$ & Atezolizumab & SoC & Toxicity \\
$\begin{array}{l}\text { IONESCO } \\
\text { (NCT03030131) }\end{array}$ & IB-II & $\mathrm{N}=81$ & Durvalumab & SoC & R0 resection \\
$\begin{array}{l}\text { CANOPY N (NCT } \\
\text { 03968419) }\end{array}$ & IB-IIIA & $\mathrm{N}=110$ & Canakinumab +/- & SoC & MPR \\
\hline
\end{tabular}

SoC, standard of care; MPR, major pathologic response; CT, chemotherapy; RT, radiation therapy; SBRT, stereotactic body radiation therapy; PFS, progression free survival; pCR, pathologic complete response; EFS, event free-survival; DFS, disease free survival.

Table 2 Randomized phase III clinical trials investigating neoadjuvant immune checkpoint inhibitors in combination with platinum-doublet chemotherapy in patients with operable NSCLC

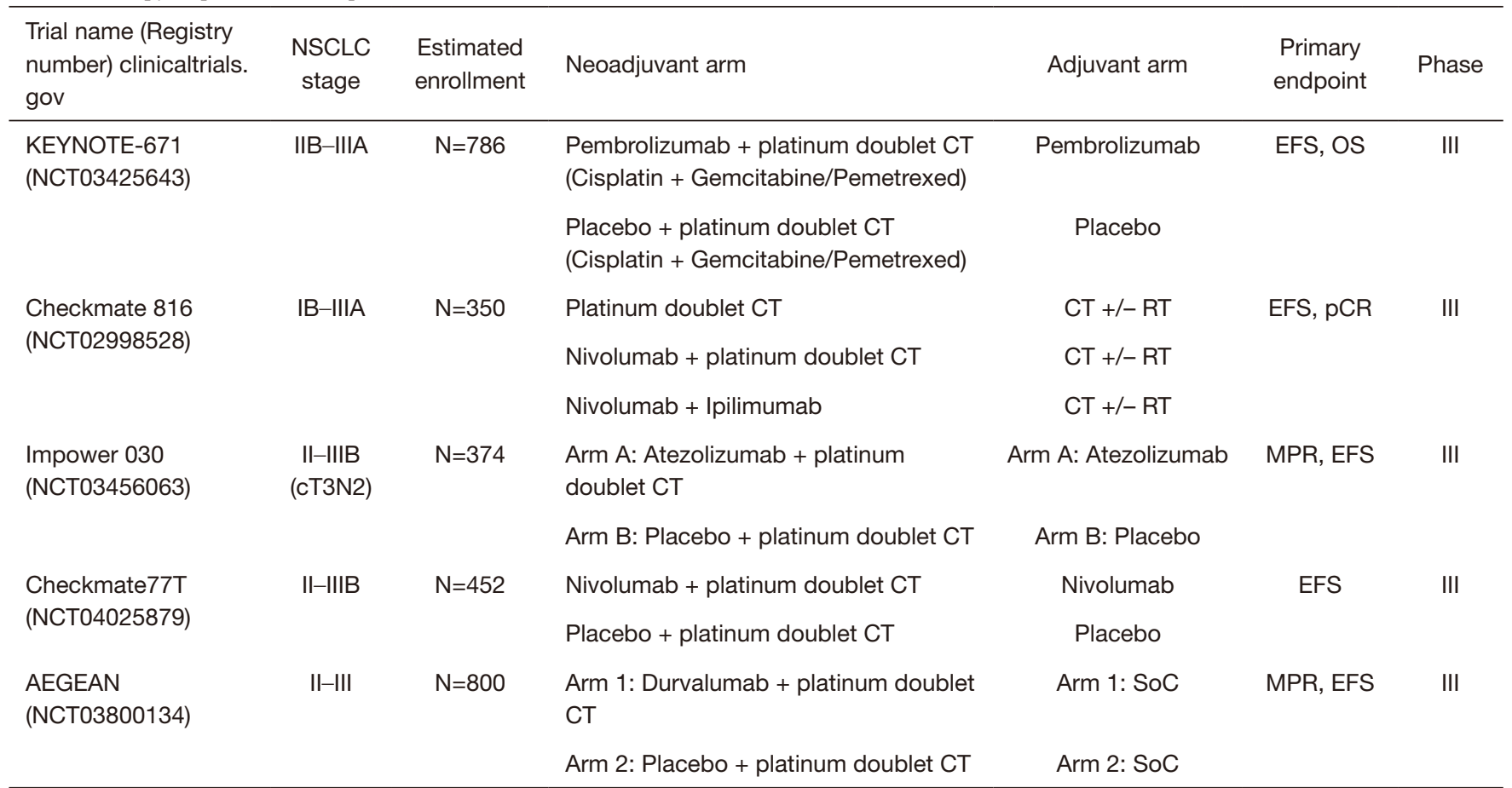

CT, chemotherapy; RT, radiation therapy; EFS, event free-survival; OS, overall survival; pCR, pathologic complete response; MPR, major pathologic response; SoC, standard of care.

\section{Tissue-based biomarkers}

\section{Tumor and stromal cell PD-L1 expression}

The PD-1 immune checkpoint receptor is expressed on activated lymphocytes while its ligand PD-L1 is expressed on immune cells such as $\mathrm{T}$ cells, B cells, macrophages, and dendritic cells and also on a wide range of tumor cells $(24,25)$. Treatment with PD-1 and PD-
L1 ICIs is designed to facilitate immune clearance of tumors that rely on these checkpoint proteins to avoid immunosurveillance (26). Several studies have evaluated immunohistochemical (IHC) staining of PD-L1 on tumor cells and tumor-infiltrating immune cells as a biomarker of response to ICIs in the metastatic setting (27-38). To date, with very few exceptions, PD-L1 expression has been used as the main selection marker to predict responses to first- 

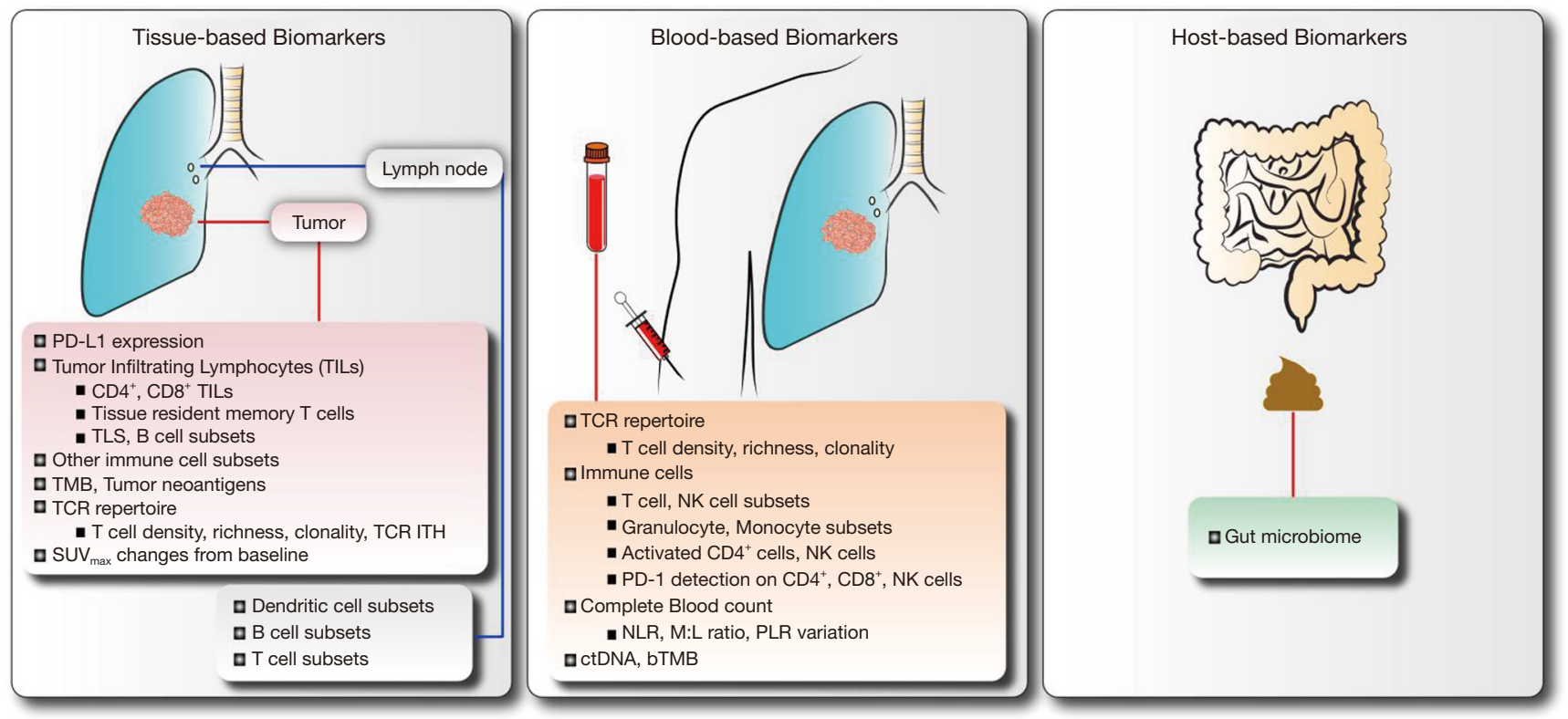

Figure 1 Biomarkers under investigation for neoadjuvant immune checkpoint inhibitors in operable NSCLC. PD-L1, programmed cell death-ligand 1; TILs, tumor infiltrating lymphocytes; TLS, tertiary lymphoid structures; TMB, tumor mutation burden; TCR, T cell receptor; ITH, intratumoral heterogeneity; $\mathrm{SUV}_{\max }$, maximum standardized uptake values; NK, natural killer cells; PD-1, programmed cell death-1; NLR, neutrophil to lymphocyte ratio; M,L, myeloid to lymphoid ratio; PLR, platelet to lymphocyte ratio; ctDNA, circulating tumor DNA; bTMB, blood-based tumor mutation burden.

line therapy for metastatic NSCLC. In a phase I clinical study, $36 \%$ of patients with $\geq 5 \%$ PD-L1 expression on NSCLC tumors prior to therapy experienced a response to anti-PD-1 treatment, while patients whose tumors failed to express detectable levels of PD-L1 did not benefit from therapy (39). In patients with metastatic NSCLC, higher levels of tumor PD-L1 expression correlated with improved outcomes to pembrolizumab (anti-PD-1 antibody) treatment $(33,34)$.

The utility of PD-L1 as a biomarker of response to neoadjuvant ICIs in NSCLC is being investigated (16-22). In the first feasibility study of 21 patients with operable NSCLC treated with neoadjuvant nivolumab, there was no association between MPR and expression of PD-L1 in pretreatment tumor biopsies (16). In this study, PDL1 staining and multispectral immunofluorescence were performed on tumor sections to analyze PD-L1 expression on tumor and immune cells (16). While MPR was observed in both $\mathrm{PD}-\mathrm{L} 1$ positive and negative tumors, in one case, the pretreatment biopsy specimen showed PD-L1 negative tumor cells but PD-L1 positive tumor infiltrating immune cells (16). Analysis of the matched posttreatment surgical specimen showed high influx of $\mathrm{CD} 8^{+} \mathrm{T}$ cells and infiltrating immune cells expressing elevated levels of PDL1 as compared to the pretreatment biopsy specimen, suggesting perhaps an adaptive immune response (16). In the LCMC3 (NCT02927301) study, pathological tumor regression and MPR were observed in resected NSCLCs after two doses of neoadjuvant atezolizumab irrespective of pretherapy PD-L1 expression (17). In a small-scale phase II clinical trial (NCT02904954) evaluating neoadjuvant durvalumab (anti-PD-L1 antibody) alone or combined with stereotactic body radiation therapy (SBRT) followed by adjuvant durvalumab in 34 patients with stage I-IIIA NSCLC, 47\% patients achieved MPR in resected tumors following combination therapy as compared to none following durvalumab alone, and a greater number of patients treated with combined therapy had tumors with PD-L1 expression $\geq 25 \%$ (20). Initial results of the phase I study MK3475-223 (NCT02938624) (19) showed that two doses of neoadjuvant pembrolizumab induced MPR in $40 \%$ of treated patients (4/10) and no correlation was observed between the levels of pretherapy PD-L1 and pathologic responses. Preliminary results from the NEOSTAR (NCT03158129) study suggested that some patients whose tumors expressed elevated pretreatment PD-L1 levels 
showed radiographic response and MPR to ICIs, compared to patients with lower pretreatment PD-L1 tumor expression (18). In patients with resectable NSCLC treated with neoadjuvant sintilimab, baseline PD-L1 expression in stromal cells correlated with pathologic response and greater pathologic regression was observed in patients with elevated baseline PD-L1 expression (21). In another study testing neoadjuvant atezolizumab plus chemotherapy, MPR was observed regardless of PD-L1 tumor expression (22). The variability in the results from these small-scale studies may be due to one or more factors, including tissue availability prior to therapy, tumor histology and genomic features, specific inhibitor/s administered, schedule and length of neoadjuvant ICI therapy, as well as the tissue analysis for pathologic tumor regression. Consequently, the potential role of pretreatment PD-L1 expression as a biomarker of response to neoadjuvant ICIs in resectable NSCLC remains to be validated in larger prospective studies.

\section{${ }^{18}$ F-FDG PET-CT parameters}

${ }^{18}$ F-FDG (fluorodeoxyglucose) $\mathrm{SUV}_{\max }$ (maximum standardized uptake values) has been shown to have potential value as a noninvasive, clinical indicator of tumor immunometabolic phenotypes in patients with resectable NSCLC (40). Recent studies have demonstrated that a tumor metabolic response by ${ }^{18} \mathrm{~F}-\mathrm{FDG}$ may predict the efficacy and survival after nivolumab treatment in patients with metastatic NSCLC $(41,42)$, however the association between changes in $\mathrm{SUV}_{\max }$ following neoadjuvant ICIs and pathologic tumor regression has not been fully investigated. Gao et al. recently reported a significant correlation between a reduction in $\mathrm{SUV}_{\max }$ of primary tumor from baseline to post neoadjuvant sintilimab and pathologic tumor responses, suggesting that $\mathrm{SUV}_{\max }$ reduction after neoadjuvant treatment could be predictive of response to neoadjuvant PD-1 blockade (21). While these initial findings are informative, additional investigations of the potential role of $\mathrm{SUV}_{\text {max }}$ changes in predicting tumor response to neoadjuvant immune-based therapies in larger clinical cohorts are needed.

\section{Tumor infiltrating immune cells}

Tumor-infiltrating lymphocytes (TILs) represent host antitumor immune response and without them ICIs cannot exert their antitumor effects (43). In patients with early- stage NSCLC, higher infiltration of both $\mathrm{CD} 4^{+}$and $\mathrm{CD} 8^{+}$ TILs have been shown to be prognostic of improved survival outcomes (44), whereas a higher proportion of regulatory $\mathrm{T}$ cells (FoxP3 ${ }^{+}$TILs) relative to total TILs in tumors from stage I NSCLC patients was associated with poor survival and tumor recurrence (45). Recently, higher levels of $\mathrm{CD}^{+}$and cytotoxic $\mathrm{CD}^{+}{ }^{+} \mathrm{CD} 8^{+}$TILs were found in NSCLC tumors resected following neoadjuvant nintedanib plus platinum-based chemotherapy in patients who were alive as compared to the patients who died (15). Other studies have shown a high density of tissue-resident memory cells $\left(\mathrm{CD} 8^{+} \mathrm{CD} 103^{+}\right)$as prognostic factor for superior survival outcomes in patients with early-stage NSCLC $(46,47)$. Cell-based studies revealed this TIL subset was cytotoxic towards autologous tumor cells in the context of PD-1/PD-L1 axis blockade (46,47), suggesting that $\mathrm{CD} 8^{+} \mathrm{CD} 103^{+}$tissue-resident memory $\mathrm{T}$ cells may have a role in promoting intratumoral cytolytic immune responses and that the use of ICIs may reverse tumorinduced T cell exhaustion in NSCLCs (46).

Early results of a recent phase II randomized study (NCT02904954) indicated that treatment with neoadjuvant durvalumab plus SBRT was associated with elevated levels of dendritic cells, myeloid cells, and fibroblasts as compared to the levels noted in tumors treated with durvalumab alone (20). Tumors that achieved MPR showed greater immunoscore and higher levels of dendritic cells and HLA gene expression, suggesting that, perhaps, sub-ablative doses of neoadjuvant radiation may enhance immune responses in NSCLCs (20). Initial results of exploratory analyses from the NEOSTAR (NCT03158129) study suggested that neoadjuvant nivolumab plus ipilimumab treatment was associated with higher levels of $\mathrm{CD}^{+}$TILs along with increased frequency of $\mathrm{CD}^{+} \mathrm{CD} 103^{+}$tissueresident memory and effector memory $\mathrm{CD} 4^{+} \mathrm{CD} 27^{-} \mathrm{CD} 28^{+}$ $\mathrm{T}$ cells in resected tumors as compared to levels in tumors resected following nivolumab monotherapy (18). Early findings from the LCMC3 study (NCT02927301) (17) indicated that MPR following neoadjuvant atezolizumab was associated with a significant expansion of dendritic cell and B cell subsets in resected lymph nodes (48). Patients whose tumors achieved MPR also had lower frequency of $\mathrm{CD} 3^{+} \mathrm{CD} 40^{+} \mathrm{CD} 25^{+}$and higher frequency of $\mathrm{CD}^{+} \mathrm{CD} 27^{+} \mathrm{CD} 45 \mathrm{RO}^{+} \mathrm{T}$ cell subsets in the resected lymph nodes (48), suggesting a possible role for lymph node specific biomarkers that may predict response to neoadjuvant ICIs. The results of these correlative studies (Figure 1) are preliminary and remain to be validated in 
larger randomized cohorts of patients.

\section{Tumor mutation burden, neoantigens, and $T$ cell receptor repertoire}

Tumor mutation burden (TMB) refers to the total number of missense somatic mutations within tumor genome that gives rise to tumor-specific neoantigens which in turn can activate the host $T$ cell response against tumor (49). Lung squamous cell carcinomas and lung adenocarcinomas, which can be caused by chronic mutagenic exposure (tobacco smoking), have been shown to have one of the highest somatic mutation burden (50), and in some studies, elevated TMB has been found to be associated with clinical benefit of ICIs in patients with advanced NSCLC $(51,52)$. The influence of high tumor mutational landscape on the clinical response to ICIs in advanced NSCLC has been the focus of recent investigative efforts (53).

Some small-scale studies of neoadjuvant ICIs have investigated the association between tissue TMB and responses to therapy. In the pilot study of 21 patients with resectable NSCLC treated with neoadjuvant nivolumab, MPR was significantly associated with TMB on pretreatment tumor biopsies (16). Patients with MPR had significantly higher TMB than those without MPR (16). The candidate mutation-associated neoantigens (MANAs) predicted to be produced as a result of somatic gene alterations correlated with tumor pathologic regression, and a greater number of predicted MANAs in pretreatment tumors was associated with a lower percentage of residual viable tumor after neoadjuvant nivolumab (16). In the LCMC3 study (NCT02927301), TMB at baseline or surgery was not found to correlate with MPR or pathological tumor regression following neoadjuvant atezolizumab, and no significant associations were noted between tumor genomic aberrations and MPR (17). Additional larger studies are needed, and it is critical to consider that several factors may limit the use of TMB as a biomarker of response to neoadjuvant ICIs, including the lack of standard threshold for high TMB, variability in the approaches to genetic sequencing, and the turnaround time required for tumor sequencing results.

Recent studies have also investigated the relationship between neoantigen heterogeneity and the response to ICIs. Clonal neoantigens are the product of nonsynonymous mutations carried by all cancer cells in a tumor, whereas subclonal antigens represent branch mutations that arise later in tumor development and are expressed by only a subset of tumor cells (54). McGranahan et al. (11) reported that patients whose advanced NSCLC possessed elevated tumor clonal neoantigen load and low neoantigen ITH (Intratumoral Heterogeneity), which refers to genetic and biological diversity within single tumor specimen as a result of tumor cell evolution (55), had a greater response to ICI treatment and longer OS (11). The authors also observed an association between elevated clonal neoantigen load and longer survival in patient cohort of patients with earlystage NSCLCs, supporting further studies investigating the role of clonal neoantigens as potential biomarker of tumor response to neoadjuvant ICIs in patients with resectable NSCLC.

The $\mathrm{T}$ cell receptor (TCR) recognizes tumor neoantigens as peptides bound to major histocompatibility (MHC) molecules (56-58). TCR repertoire features, including the frequency of $\mathrm{T}$ cells within a tumor (density), the diversity of $\mathrm{T}$ cells (richness), and the tumor reactive $\mathrm{T}$ cell clonal expansion (clonality), are being evaluated as markers of clinical benefit from ICIs. In patients with stage IIB-IV NSCLC, changes in TCR clonality have been reported to be associated with acquired resistance to ICIs (59). Analysis of NSCLCs that developed acquired resistance after an initial response to anti-PD1 therapy showed dynamic changes in the TCR clonality induced by loss of immunogenic MANAs in resistant tumors (59). Other studies have investigated the distribution of the $T$ cell repertoire to determine TCR ITH and its relationship with patient outcomes. A study using multiregion TCR sequencing of early-stage lung adenocarcinomas found that significant TCR ITH, as determined by assessment of $\mathrm{T}$ cell density and clonality, was positively associated with predicted neoantigen ITH (60). A greater TCR ITH was associated with elevated risk of disease recurrence after surgical resection (60), highlighting a potential role of TCR ITH in influencing clinical outcomes of patients with earlystage lung cancers.

Much less information is known regarding the role of TCR features as potential biomarkers of response to neoadjuvant ICIs in NSCLC patients. In patients with NSCLC treated with neoadjuvant nivolumab (16), TCR sequencing was performed to evaluate the influence of treatment on $\mathrm{T}$ cell clone repertoire in the tumor and peripheral blood at the time of resection. In resected tumors with MPR, a higher abundance of $\mathrm{T}$ cell clones that were also shared with peripheral blood and higher clonality of $\mathrm{T}$ cells were found following neoadjuvant nivolumab $(16,61)$. Large-scale studies of tumor and peripheral TCR 
richness, density, and clonality following neoadjuvant ICIs in resectable NSCLC will shed light on the utility of these parameters in serving as biomarkers of tumor responsiveness to ICIs.

\section{Tertiary lymphoid structures and B lymphocytes}

B lymphocytes are one of the most prevalent cells in the NSCLC immune infiltrate and are detected in all stages of lung cancer development $(62,63)$, however, their presence differs depending on the stage and histological subtypes $(64,65)$. B cells are frequently found in tertiary lymphoid structures (TLS) located at the tumor-immune interface (66). Studies have demonstrated a correlation between a high density of follicular B cells and long-term survival in both early- and advanced-stage NSCLC patients who are treated with chemotherapy (67). Recent work has demonstrated that $\mathrm{B}$ cell subpopulations can exert a dual role in tumorigenesis. B cells can enhance effector $\mathrm{T}$ cell responses directly by producing immunostimulatory cytokines (e.g., IL-2, IL-4, IFN- $\gamma$, and TNF- $\alpha$ ) and indirectly by presenting antigen to $\mathrm{T}$ cells (68). B cells can also differentiate into plasma cells that produce antibodies that bind to tumor cells and activate complement or promote antibody-dependent cellular cytotoxicity (68). Alternatively, regulatory B cells may impair an antitumor immune response by producing immunosuppressive cytokines, such as IL-10 and TGF- $\beta$ (69). Recent work shed light on the interplay between tumor-infiltrating $\mathrm{B}$ cells (TIL-Bs) and CD4 ${ }^{+}$TILs within the NSCLC microenvironment. Bruno et al. (70) demonstrated that the density of TIL-Bs in NSCLCs is greater than B cell infiltration into adjacent tissues and they noted distinct $\mathrm{CD}^{+}$TIL phenotypes in response to TIL-Bs. Activated TIL-Bs $\left(\mathrm{CD} 19^{+} \mathrm{CD} 20^{+} \mathrm{CD} 69^{+} \mathrm{CD} 27^{+} \mathrm{CD} 21^{+}\right)$were associated with an effector T-cell response $\left(\mathrm{IFN} \gamma^{+}\right)$in the activated and antigen-associated CD4 ${ }^{+}$TIL subset, whereas, exhausted TIL-Bs $\left(\mathrm{CD} 19^{+} \mathrm{CD} 20^{+} \mathrm{CD} 69^{+} \mathrm{CD} 27^{-} \mathrm{CD} 21^{-}\right)$ were associated with regulatory FoxP $3^{+} \mathrm{CD} 4^{+}$TILs (70). These findings highlight a role for TIL-Bs in influencing the phenotype and function of $\mathrm{CD}^{+}{ }^{+}$TILs within the tumor microenvironment of NSCLCs that may have important implications on tumor responses to therapy.

The relationship between $\mathrm{B}$ cells and tumor responses to ICI therapy has been recently investigated (71). In a recent work using tumor specimens from patients with high-risk resectable melanoma and metastatic renal cell carcinoma (RCC) treated with presurgical ICIs, Helmnik and colleagues (72) discovered that B cell signatures were enriched in tumors of patients who responded to treatment when compared to nonresponders. B cells were localized to TLS and results of bulk and single-cell RNA sequencing showed clonal expansion and unique functional states of B cells in responding tumors. In another study recently published, Cabrita et al. (73) studied how B cells influence antitumor responses in metastatic melanomas and demonstrated that patients whose tumors were enriched in both $\mathrm{CD}^{+} \mathrm{T}$ cells and $\mathrm{CD} 20^{+} \mathrm{B}$ cells within TLS had improved survival and increased responses to immunotherapy. Similar results were found in other cancers. Petitprez et al. (74) constructed gene expression profiles on several different sarcoma subtypes and found that the presence of TLS enriched in B cells was associated with improved responses to anti-PD-1 therapy and prolonged patient survival. Together, these findings highlight the importance of developing potential therapeutic strategies to induce the formation of TLS within tumors as a clinically useful approach to improve responses to cancer immunotherapy.

Extending the abovementioned observations to earlystage NSCLC cohorts will provide novel insight regarding the role of $\mathrm{B}$ cells and TLS in promoting tumor response to ICIs and an opportunity for biomarker discovery. Mechanistic studies will be critical to uncover whether enhancing B cell responses and TLS formation within lung tumors could serve as a combinatorial approach to neoadjuvant ICIs for patients with operable NSCLC.

\section{Blood-based biomarkers}

The use of tissue biopsies for biomarker discovery and development requires invasive procedures that may result in patient discomfort, delayed treatment, and increased costs. Often, the quantity and quality of tissues removed are insufficient for extensive correlative analyses. Bloodbased biomarkers provide a non-invasive, cost-effective and time-efficient method to identify patients likely to respond to immunotherapy. Blood-based biomarkers also facilitate longitudinal studies and biomarkers analyses may be performed at different treatment time points with relative ease.

\section{Peripheral TCR repertoire}

Several studies have evaluated the characteristics of circulating $T$ cells in patients with NSCLC and their 
relationship with survival outcomes. Metrics of the TCR repertoire, including density, diversity, and clonality, were analyzed by sequencing of the CDR3 (complementarity determining region 3 ) regions in the TCR- $\beta$ chain involved in antigen binding and correlated with response to therapy $(16,18,61,75,76)$. A recent report demonstrated that a higher density of $\mathrm{T}$ cells in the peripheral blood of patients with early-stage lung adenocarcinomas correlated with longer OS (76). Other investigations have focused on understanding the relationship between the $\mathrm{T}$ cell repertoire and tumor response to ICIs. Patients with advanced/metastatic NSCLC who possessed elevated peripheral $\mathrm{PD}-1^{+} \mathrm{CD} 8^{+} \mathrm{T}$ cell diversity in blood samples prior to ICI therapy had a greater response to treatment and significantly longer PFS compared to patients with low $\mathrm{T}$ cell diversity (77). Furthermore, patients who had increased PD $-1^{+} \mathrm{CD}^{+}$TCR clonality after ICI therapy also experienced longer PFS (77).

In the pilot study, evaluating neoadjuvant nivolumab in patients with resectable NSCLC, the investigators reported that patients whose tumors achieved MPR at surgery following neoadjuvant ICI therapy possessed higher frequency of $\mathrm{T}$ cell clones shared between tumor and peripheral blood (16). MPR following neoadjuvant nivolumab was also associated with a systemic expansion of $\mathrm{T}$ cell clones reactive to new MANAs that were not present in the periphery prior to treatment (16). Initial results from analyses performed in a limited number of samples collected from early-stage NSCLC patients treated with neoadjuvant nivolumab and nivolumab plus ipilimumab from the NEOSTAR trial (NCT03158129), revealed that pretreatment $\mathrm{T}$ cell richness in periphery positively correlated with increased posttreatment $\mathrm{T}$ cell richness in resected tumors, suggesting perhaps, potential ICIinduced $\mathrm{T}$ cell infiltration from peripheral blood to treated tumors $(18,75)$. Together, these findings, while in need to be validated in larger patient cohorts, suggest that homing of peripheral $\mathrm{T}$ cell clones to tumor following neoadjuvant ICIs may contribute to an effective antitumor immunity and, in some cases, to pathologic responses (61).

\section{Peripheral immune cells}

Dynamic changes in peripheral immune cell populations following neoadjuvant immunotherapy and their association with tumor response to treatment are also being investigated in patients with resectable NSCLC for biomarker discovery. In these studies, blood samples were subjected to plasma- based cytokine arrays and analysis of PBMCs (peripheral blood mononuclear cells) by flow cytometry to identify the immunophenotypes of peripheral immune cells potentially associated with efficacy of ICIs $(48,78)$. In the LCMC3 study (NCT02927301), blood samples were collected from patients pre- and posttreatment with neoadjuvant atezolizumab to investigate peripheral immunophenotyping and explore therapy-induced modulation of subsets of immune cell populations (48). A lower frequency of specific $\mathrm{T}$ cell $\left(\mathrm{G} / \mathrm{D}^{+} \mathrm{CD} 3^{+} \mathrm{CD} 8^{+} \mathrm{CD} 56^{+} \mathrm{CD} 16^{+}\right)$and natural killer (NK) cell $\left(\mathrm{CD} 16^{+} \mathrm{CD} 56^{+} \mathrm{CD} 244^{+} \mathrm{CD} 314^{+} \mathrm{CD} 161^{+}\right)$ subsets were found in baseline samples from patients who achieved MPR compared to those who did not (48). This study also demonstrated an expansion in NK cell $\left(\mathrm{CD} 314^{+} \mathrm{CD} 56 / 16^{+}\right)$and granulocyte $\left(\mathrm{CD} 33^{+} \mathrm{HLA}-\right.$ $\left.\mathrm{DR}^{+} \mathrm{CD} 11 \mathrm{~b}^{+} \mathrm{CD} 16^{+}\right)$subsets, and a contraction of monocyte subset $\left(\mathrm{CD} 56^{+} \mathrm{CD} 13 / 14^{+} \mathrm{CD}^{+}\right)$in the peripheral blood of patients with MPR in resected tumors. Interestingly, granulocyte $\left(\mathrm{HLA}-\mathrm{DR}^{+} \mathrm{CD} 33^{+} \mathrm{CD} 16^{+}\right)$and dendritic cell (HLA-DR ${ }^{+} \mathrm{CD} 33^{+} \mathrm{CD} 11 \mathrm{~b}^{+} \mathrm{CD} 15^{+}$) subsets were expanded in patients who developed immune-related adverse events to neoadjuvant therapy (48). Preliminary results of correlative studies evaluating immune modulation in peripheral blood samples collected pre- and post-neoadjuvant chemotherapy plus nivolumab from patients with stage IIIA NSCLC from the NADIM trial (NCT03081689) have been reported (78). Peripheral densities of activated $\mathrm{CD}^{+} \mathrm{T}$ cells $\left(\mathrm{CD} 69^{+}\right)$and $\mathrm{NK}$ cells $\left(\mathrm{CD} 107 \mathrm{a}^{+}\right)$were reduced post neoadjuvant therapy in patients who achieved pCR in resected tumors (78). Also, the authors found a decrease in the expression of $\mathrm{PD}-1$ on peripheral $\mathrm{CD}^{+}, \mathrm{CD}^{+}$, and $\mathrm{NK}$ cells post neoadjuvant chemo-immunotherapy in patients who achieved pCR in resected tumors (78). Investigation of peripheral immunophenotyping in larger patient cohorts and across trials testing neoadjuvant immunotherapies are needed to validate these findings and determine whether various immune cell populations may serve as biomarkers of therapeutic efficacy.

\section{Complete blood count (CBC)}

Absolute values of circulating blood cells collected during routine laboratory blood draws and ratios of complete blood cell counts have been investigated as potential markers of tumor response to ICIs (78-82). Reports examining the immune infiltrate in NSCLC indicate that neutrophils are among the most abundant cells found in NSCLCs $(63,83)$. Neutrophil counts are elevated in peripheral blood as a 
result of local inflammation within the tumor (84). For example, granulocyte colony-stimulating factor (G-CSF) produced by tumors induces neutrophil release from the bone marrow to periphery, resulting in elevated neutrophils in the blood (85). High neutrophil counts were found to be indicative of high tumor burden and inferior OS in a cohort of patients with surgically resected NSCLC from the ICON (ImmunogenomiC PrOfiling of NSCLC) project (86). The number of tumor infiltrating $\mathrm{CD} 8^{+}$cytotoxic $\mathrm{T}$ cells was also reduced and was accompanied by reduced expression levels of CD8A, CD8B, GZMA, GZMB, and IFN $\gamma$-related genes (86).

There is available evidence suggesting that the measurement of blood neutrophils may be a biomarker of tumor response to therapy. In advanced NSCLC, both a high blood neutrophil-to-lymphocyte ratio (NLR) and a high myeloid-to-lymphoid (M:L) ratio prior to antiPD-1 therapy were associated with poor PFS and OS $(81,82)$. The mechanisms whereby neutrophils contribute to NSCLC progression and resistance to therapy are not fully understood. Studies suggest that the phenotype of blood neutrophils is dramatically different from that of tumor-associated neutrophils (TANs) in that the latter exhibit an activated phenotype [CD62L(lo)CD54(hi)] and express a distinct pattern of chemokine receptors, including upregulation of CCR5, CCR7, CXCR3, and CXCR4 (87). However, data generated from experimental lung cancer models suggest that TANs may transition from the cytotoxic phenotype observed early in the disease and acquire protumorigenic properties as tumors progress. Mishalian and colleagues (88) found that TANs isolated from latestage preclinical Lewis lung carcinoma models produced lower levels of cytotoxic effector protein TNF- $\alpha, \mathrm{H}_{2} \mathrm{O}_{2}$, and $\mathrm{NO}$ when compared to early-stage tumors, and depletion of neutrophils at later stages of tumor development inhibited tumor growth.

Initial results of correlative studies exploring the changes in peripheral blood count cells in patients with early-stage NSCLC treated with neoadjuvant ICIs have been recently reported. Laza-Briviesca et al. (78) found a significant decrease in the total levels of peripheral leucocytes, eosinophil, monocytes, neutrophils, hemoglobin, and platelets after neoadjuvant chemotherapy plus nivolumab in patients from the NADIM study (NCT03081689), however, no significant changes were noted in lymphocytes, basophils, and lactate dehydrogenase (LDH) levels (78). Posttreatment peripheral NLR, M:L ratio, and platelets-to-lymphocytes ratio (PLR) were decreased. The variation in PLR (decrease in posttreatment as compared to pretreatment values) was significantly lower in the blood of patients whose tumors achieved $\mathrm{pCR}$, as compared to those whose tumors achieved pathological incomplete response ( $\mathrm{pIR}$ ) with $>10 \%$ viable tumor (78). These results require additional validation in larger studies of neoadjuvant immunotherapy and continued examinations of CBC results in expanded patient cohorts will improve our understanding on the utility of this test as a biomarker for neoadjuvant immune-based therapies.

\section{Circulating tumor DNA}

ctDNA (circulating tumor DNA) in blood samples has attracted considerable interest as a sensitive, non-invasive biomarker for assessing tumor response to therapy and clinical benefit. ctDNAs are cell-free DNA molecules that match the somatic mutations identified in tumors and are released into the bloodstream by apoptotic or necrotic tumor cells (89). Recent efforts investigated the feasibility of bTMB (blood-based TMB) as a predictive biomarker of tumor response to therapy $(90,91)$, based on the notion that bTMB measured from ctDNA sequencing allows non-invasive and expedited testing that may capture the tumor genomic landscape. In some of these studies, ctDNA has been quantified using error-suppressed deep sequencing data which were analyzed for allelic fraction of tumor-derived DNA within the total cell free DNA in the plasma (92). For bTMB assay, the same hybridizationcapture methodology as the FDA-approved FoundationOne (F1) CDx NGS assay was used and it targeted $1.1 \mathrm{Mb}$ of genomic coding sequence. The bTMB score was determined by identifying all base substitutions present at an allele frequency of $\geq 0.5 \%$ across the coding region of approximately $1.1 \mathrm{Mb}$ and filtering out germline events (90). In a retrospective analysis of two large randomized trials of previously treated, metastatic NSCLC patients receiving immunotherapy, bTMB reproducibly identified patients who had significant improvements in PFS from anti-PD-L1 therapy (90). Similar findings were reported by Wang et al. (93) who identified high bTMB as an indicator of improved objective response rates and prolonged PFS in a separate cohort of 50 advanced NSCLC patients treated with ICIs. In the perioperative setting, the use of bTMB as a potential biomarker of response to therapy may be limited simply due to the reduced tumor burden resulting in lower ctDNA shedding into circulation as compared to more advanced disease stages (94). Ongoing studies are investigating the role of bTMB assessed by ctDNA analysis 
in predicting responses to induction immunotherapy in patient with resectable NSCLC.

The relationship between levels of ctDNA in peripheral blood as a biomarker for early detection of molecular residual disease (MRD) and onset of tumor relapse is also being investigated in NSCLC patients $(94,95)$. Absence or reduced ctDNA levels have been shown to be a potential predictor of prolonged survival in NSCLC patients treated with ICIs $(92,96)$. Our group has shown that in early-stage NSCLC patients, the detection of ctDNA in peripheral blood as early as 4 weeks following tumor resection was associated with an elevated risk of disease recurrence (97), highlighting the utility of ctDNA detection for early assessment of tumor relapse in patients who have undergone curative surgery of their NSCLC. A recent study evaluating ctDNA in the blood of patients with NSCLC treated with neoadjuvant nivolumab demonstrated that levels of ctDNA were significantly reduced in patients who experienced a pathologic response to ICI, whereas ctDNA remained the same or increased in patients whose tumors were refractory to treatment (98). Responders also had evidence of clonal expansion of intratumoral $\mathrm{T}$ cell clones in peripheral blood, which positively correlated with reduced ctDNA level. The authors also demonstrated that tracking peripheral ctDNA predicted therapeutic outcome 8.7 weeks earlier as compared to detection by radiographic imaging (98). These results are encouraging and illustrate the importance of investigating ctDNA as a biomarker of response to induction immunotherapies in expanded patient cohorts.

\section{Host-based biomarkers}

Accumulating evidence suggests that the composition of bacteria residing in the gut may play a key role in determining the efficacy of anticancer therapy, including ICIs $(99,100)$. Gut microbial-derived metabolites have been shown to have a profound effect on systemic immune function (101). Favorable microbiome species may improve the efficacy of ICIs by activating dendritic cells and increasing $\mathrm{CD} 8^{+} \mathrm{T}$ cell recruitment to the tumor microenvironment (102), inducing IL-12-dependent Th1 immune response (103), and augmenting $\mathrm{T}$ cell responses (104). In patients with metastatic NSCLC and RCC, administration of antibiotics along with anti-PD-1/ PD-L1 therapy altered gut microbiome and deterred tumor responses to ICIs (105). FMTs (Fecal Microbiota Transplantation) from responding patients to mice or oral administration of microbiome in combination with FMT from nonresponding patients reinstituted response to ICI therapy by inducing tumor infiltration of $\mathrm{CR}^{+}{ }^{+} \mathrm{CXCR} 3^{+} \mathrm{CD} 4^{+} \mathrm{T}$ cells through an IL-12-dependent signaling pathway (105). PD-1 blockade triggered local and systemic recall of Th1 immune response against specific microbiome that may enhance cancer immunosurveillance (105).

In a cohort of Chinese patients with advanced NSCLC, responders to PD-1 inhibition showed greater gut microbiome diversity at baseline and a stable microbiome composition during treatment (106). The authors also found that systemic memory $\mathrm{CD} 8^{+} \mathrm{T}$ cells and NK cells exerted an antitumor treatment effect (106). These early correlative studies demonstrate associations between gut microbiome composition and tumor responsiveness to ICIs and investigative efforts are ongoing to evaluate the impact of gut microbiome on efficacy of neoadjuvant ICIs and ICI-related toxicity in patients with operable NSCLC (NCT03158129).

\section{Conclusions, current challenges, and future directions}

The results generated from recent clinical trials indicate that NSCLCs are one of the most responsive cancers to ICIs. Indeed, the advent of ICIs has dramatically improved outcomes for patients with advanced NSCLC. Now, ICIs are undergoing evaluation as perioperative therapy for patients with resectable disease using potential surrogate endpoints for rapid evaluation of clinical efficacy. The initial results of these studies are encouraging, however, they also reveal that a significant fraction of NSCLC patients is refractory to ICI therapy. Consequently, much research effort is being directed toward identifying biomarkers that can be used to inform the therapeutic decision-making process and maximize the clinical benefit of ICIs.

In this review, we discussed candidate biomarkers that are emerging from the initial trials of perioperative ICIs for early-stage NSCLC or are being investigated in ongoing trials (Figure 1). A comparison between the initial studies indicates that there is some intertrial variability in MPR, which may affect biomarker discovery. Whether these differences are a product of differing sample sizes, neoadjuvant therapies, oncogenic drivers, tumor histology, doses and schedule of therapy, or the lack of a standardized approach for MPR evaluation remains unclear. Several efforts are underway to shed light on these issues and establish a standard approach for the evaluation 
of pathologic tumor regression following neoadjuvant therapies (107). There are also issues associated with sample procurement. In some instances, there is a lack of sufficient specimens to run all of the biomarker tests. Also, the absence of paired samples at different time points of therapy can derail analyses of dynamic changes in biomarker levels. Standardization of collection, handling, and processing of tissue biopsies is critical. Immunotherapy studies should incorporate careful analysis of tumor tissuebased (tumor cells, microenvironment, and adjacent uninvolved lung), blood-based, and host intrinsic factors to define the predictors of response to ICIs. Having a larger panel of biomarkers with combined analyses may improve the predictive potential of these factors. With further optimization of immune-based treatment strategies and the development of novel therapy combinations to treat earlystage NSCLC, biomarker investigation will play a key role in rational selection of patients for treatment, to further refine therapy and minimize unnecessary toxicities in a more personalized manner.

\section{Acknowledgments}

Funding: This work was partially supported by the NIH/ NCI P30 CA016672 Cancer Center Support Grant (CCSG), Lung SPORE grant 5 P50 CA070907, the Conquer Cancer Foundation of the American Society of Clinical Oncology (ASCO) Career Development Award 2018, the generous philanthropic contributions to the University of Texas MD Anderson Cancer Center Lung Cancer Moon Shot Program, the University of Texas MD Anderson Cancer Center Khalifa Scholars Award (from Khalifa Bin Zayed Al Nahyan Foundation), the University of Texas MD Anderson Cancer Center Physician Scientist Program, the T.J. Martell Foundation, and the Bob Mayberry Foundation.

\section{Footnote}

Provenance and Peer Review: This article was commissioned by the Guest Editor (Mariano Provencio) for the series "Multimodal management of locally advanced N2 nonsmall cell lung cancer" published in Translational Lung Cancer Research. The article has undergone external peer review.

Peer Review File: Available at http://dx.doi.org/10.21037/ tlcr-20-573
Conflicts of Interests: All authors have completed the ICMJE uniform disclosure form (available at http:// dx.doi.org/10.21037/tlcr-20-573). The series "Multimodal management of locally advanced N2 non-small cell lung cancer" was commissioned by the editorial office without any funding or sponsorship. DLG has received consulting fee from Astellas and research funding from AstraZeneca, Janssen R\&D, Takeda, Ribon Therapeutics, Sanofi, Astellas and has participated in advisory boards for AstraZeneca and Sanofi. BS reports consulting fees from BristolMyers Squibb. TC reports speaker's fees from Society for Immunotherapy of Cancer (SITC) and Bristol-Myers Squibb, consulting fees from MedImmune/AstraZeneca and Bristol-Myers Squibb, and advisory role fees from EMD Serono and Bristol-Myers Squibb and clinical research funding to MD Anderson Cancer Center from Boehringer Ingelheim, MedImmune/AstraZeneca , EMD Serono and Bristol-Myers Squibb. The authors have no other conflicts of interest to declare.

Ethical Statement: The authors are accountable for all aspects of the work in ensuring that questions related to the accuracy or integrity of any part of the work are appropriately investigated and resolved.

Open Access Statement: This is an Open Access article distributed in accordance with the Creative Commons Attribution-NonCommercial-NoDerivs 4.0 International License (CC BY-NC-ND 4.0), which permits the noncommercial replication and distribution of the article with the strict proviso that no changes or edits are made and the original work is properly cited (including links to both the formal publication through the relevant DOI and the license). See: https://creativecommons.org/licenses/by-nc-nd/4.0/.

\section{References}

1. Herbst RS, Heymach JV, Lippman SM. Lung cancer. N Engl J Med 2008;359:1367-80.

2. Howlader N, Noone AM, Krapcho M, et al. (eds). SEER Cancer Statistics Review, 1975-2017, National Cancer Institute. Bethesda, MD. Available online: https://seer.cancer. gov/csr/1975_2017/, based on November 2019 SEER data submission, posted to the SEER web site, April 2020.

3. Uramoto H, Tanaka F. Recurrence after surgery in patients with NSCLC. Transl Lung Cancer Res 2014;3:242-9.

4. Douillard JY, Rosell R, De Lena M, et al. Adjuvant vinorelbine plus cisplatin versus observation in patients 
with completely resected stage IB-IIIA non-small-cell lung cancer (Adjuvant Navelbine International Trialist Association [ANITA]): a randomised controlled trial. Lancet Oncol 2006;7:719-27.

5. Pignon JP, Tribodet H, Scagliotti GV, et al. Lung adjuvant cisplatin evaluation: a pooled analysis by the LACE Collaborative Group. J Clin Oncol 2008;26:3552-9.

6. Group NM-aC. Preoperative chemotherapy for non-smallcell lung cancer: a systematic review and meta-analysis of individual participant data. Lancet 2014;383:1561-71.

7. Lindeman NI, Cagle PT, Aisner DL, et al. Updated Molecular Testing Guideline for the Selection of Lung Cancer Patients for Treatment With Targeted Tyrosine Kinase Inhibitors: Guideline From the College of American Pathologists, the International Association for the Study of Lung Cancer, and the Association for Molecular Pathology. J Mol Diagn 2018;20:129-59.

8. Kris MG, Johnson BE, Berry LD, et al. Using multiplexed assays of oncogenic drivers in lung cancers to select targeted drugs. JAMA 2014;311:1998-2006.

9. Doroshow DB, Sanmamed MF, Hastings K, et al. Immunotherapy in Non-Small Cell Lung Cancer: Facts and Hopes. Clin Cancer Res 2019;25:4592-602.

10. Brahmer JR. Harnessing the immune system for the treatment of non-small-cell lung cancer. J Clin Oncol 2013;31:1021-8.

11. McGranahan N, Furness AJ, Rosenthal R, et al. Clonal neoantigens elicit $\mathrm{T}$ cell immunoreactivity and sensitivity to immune checkpoint blockade. Science 2016;351:1463-9.

12. Pataer A, Kalhor N, Correa AM, et al. Histopathologic response criteria predict survival of patients with resected lung cancer after neoadjuvant chemotherapy. J Thorac Oncol 2012;7:825-32.

13. Chaft JE, Rusch V, Ginsberg MS, et al. Phase II trial of neoadjuvant bevacizumab plus chemotherapy and adjuvant bevacizumab in patients with resectable nonsquamous non-small-cell lung cancers. J Thorac Oncol 2013;8:1084-90.

14. Cascone T, Gold KA, Swisher SG, et al. Induction Cisplatin Docetaxel Followed by Surgery and Erlotinib in Non-Small Cell Lung Cancer. Ann Thorac Surg 2018;105:418-24.

15. Cascone T, Sepesi B, Lin H, et al. A Phase I/II Study of Neoadjuvant Cisplatin, Docetaxel and Nintedanib for Resectable Non-Small Cell Lung Cancer. Clin Cancer Res 2020;26:3525-36.

16. Forde PM, Chaft JE, Smith KN, et al. Neoadjuvant PD-1 Blockade in Resectable Lung Cancer. N Engl J Med
2018;378:1976-86.

17. Kwiatkowski DJ, Rusch VW, Chaft JE, et al. Neoadjuvant atezolizumab in resectable non-small cell lung cancer (NSCLC): Interim analysis and biomarker data from a multicenter study (LCMC3). J Clin Oncol 2019;37:abstr 8503.

18. Cascone T, William WN, Weissferdt A, et al. Neoadjuvant nivolumab $(\mathrm{N})$ or nivolumab plus ipilimumab (NI) for resectable non-small cell lung cancer (NSCLC): Clinical and correlative results from the NEOSTAR study. J Clin Oncol 2019;37:abstr 8504.

19. Bar J, Urban D, Ofek E, et al. Neoadjuvant pembrolizumab (Pembro) for early stage non-small cell lung cancer (NSCLC): Updated report of a phase I study, MK3475-223. J Clin Oncol 2019;37:abstr 8534.

20. Altorki N, Borczuk A, Saxena A, et al. P2.04-92 Neoadjuvant Durvalumab With or Without Sub-Ablative Stereotactic Radiotherapy (SBRT) in Patients with Resectable NSCLC (NCT02904954). J Thorac Oncol 2019;14:S746.

21. Gao S, Li N, Gao S, et al. Neoadjuvant PD-1 inhibitor (Sintilimab) in NSCLC. J Thorac Oncol 2020;15:816-26.

22. Shu CA, Gainor JF, Awad MM, et al. Neoadjuvant atezolizumab and chemotherapy in patients with resectable non-small-cell lung cancer: an open-label, multicentre, single-arm, phase 2 trial. Lancet Oncol 2020;21:786-95.

23. Provencio $M$, Nadal E, Insa A, et al. Neoadjuvant chemotherapy and nivolumab in resectable non-small-cell lung cancer (NADIM): an open-label, multicentre, singlearm, phase 2 trial. Lancet Oncol 2020;21:1413-22.

24. Pardoll DM. The blockade of immune checkpoints in cancer immunotherapy. Nat Rev Cancer 2012;12:252-64.

25. Dong Y, Sun Q, Zhang X. PD-1 and its ligands are important immune checkpoints in cancer. Oncotarget 2017;8:2171-86.

26. Sharma P, Allison JP. Immune checkpoint targeting in cancer therapy: toward combination strategies with curative potential. Cell 2015;161:205-14.

27. Teixido C, Vilarino N, Reyes R, et al. PD-L1 expression testing in non-small cell lung cancer. Ther Adv Med Oncol 2018;10:1758835918763493.

28. Herbst RS, Baas P, Kim DW, et al. Pembrolizumab versus docetaxel for previously treated, PD-L1-positive, advanced non-small-cell lung cancer (KEYNOTE-010): a randomised controlled trial. Lancet 2016;387:1540-50.

29. Herbst RS, Garon EB, Kim DW, et al. Long-Term Outcomes and Retreatment Among Patients With Previously Treated, Programmed Death-Ligand 
1-Positive, Advanced Non-Small-Cell Lung Cancer in the KEYNOTE-010 Study. J Clin Oncol 2020;38:1580-90.

30. Fehrenbacher L, Spira A, Ballinger M, et al. Atezolizumab versus docetaxel for patients with previously treated non-small-cell lung cancer (POPLAR): a multicentre, open-label, phase 2 randomised controlled trial. Lancet 2016;387:1837-46.

31. Rittmeyer A, Barlesi F, Waterkamp D, et al. Atezolizumab versus docetaxel in patients with previously treated non-small-cell lung cancer (OAK): a phase 3, openlabel, multicentre randomised controlled trial. Lancet 2017;389:255-65.

32. Spigel D, de Marinis F, Giaccone G, et al. LBA78 IMpower110: Interim overall survival (OS) analysis of a phase III study of atezolizumab (atezo) vs platinum-based chemotherapy (chemo) as first-line (1L) treatment (tx) in PD-L1-selected NSCLC. Ann Oncol 2019;30:v915.

33. Reck M, Rodriguez-Abreu D, Robinson AG, et al. Pembrolizumab versus Chemotherapy for PD-L1Positive Non-Small-Cell Lung Cancer. N Engl J Med 2016;375:1823-33.

34. Mok TSK, Wu YL, Kudaba I, et al. Pembrolizumab versus chemotherapy for previously untreated, PD-L1expressing, locally advanced or metastatic non-small-cell lung cancer (KEYNOTE-042): a randomised, open-label, controlled, phase 3 trial. Lancet 2019;393:1819-30.

35. Aguilar EJ, Ricciuti B, Gainor JF, et al. Outcomes to first-line pembrolizumab in patients with non-small-cell lung cancer and very high PD-L1 expression. Ann Oncol 2019;30:1653-9.

36. Hellmann MD, Paz-Ares L, Bernabe Caro R, et al. Nivolumab plus Ipilimumab in Advanced Non-Small-Cell Lung Cancer. N Engl J Med 2019;381:2020-31.

37. Jotte R, Cappuzzo F, Vynnychenko I, et al. Atezolizumab in Combination With Carboplatin and Nab-Paclitaxel in Advanced Squamous NSCLC (IMpower131): Results From a Randomized Phase III Trial. J Thorac Oncol 2020;15:1351-60.

38. Remon J, Passiglia F, Ahn MJ, et al. Immune Checkpoint Inhibitors in Thoracic Malignancies: Review of the Existing Evidence by an IASLC Expert Panel and Recommendations. J Thorac Oncol 2020;15:914-47.

39. Topalian SL, Hodi FS, Brahmer JR, et al. Safety, activity, and immune correlates of anti-PD-1 antibody in cancer. $\mathrm{N}$ Engl J Med 2012;366:2443-54.

40. Mitchell KG, Amini B, Wang Y, et al. (18) F-fluorodeoxyglucose positron emission tomography correlates with tumor immunometabolic phenotypes in resected lung cancer. Cancer Immunol Immunother 2020;69:1519-34.

41. Evangelista L, Cuppari L, Menis J, et al. 18F-FDG PET/ CT in non-small-cell lung cancer patients: a potential predictive biomarker of response to immunotherapy. Nucl Med Commun 2019;40:802-7.

42. Kaira K, Higuchi T, Naruse I, et al. Metabolic activity by (18)F-FDG-PET/CT is predictive of early response after nivolumab in previously treated NSCLC. Eur J Nucl Med Mol Imaging 2018;45:56-66.

43. Schalper KA, Brown J, Carvajal-Hausdorf D, et al. Objective measurement and clinical significance of TILs in non-small cell lung cancer. J Natl Cancer Inst 2015;107:dju435.

44. Hiraoka K, Miyamoto M, Cho Y, et al. Concurrent infiltration by CD8+ $\mathrm{T}$ cells and CD4+ T cells is a favourable prognostic factor in non-small-cell lung carcinoma. Br J Cancer 2006;94:275-80.

45. Petersen RP, Campa MJ, Sperlazza J, et al. Tumor infiltrating Foxp3 + regulatory T-cells are associated with recurrence in pathologic stage I NSCLC patients. Cancer 2006;107:2866-72.

46. Djenidi F, Adam J, Goubar A, et al. CD8+CD103+ tumorinfiltrating lymphocytes are tumor-specific tissue-resident memory $\mathrm{T}$ cells and a prognostic factor for survival in lung cancer patients. J Immunol 2015;194:3475-86.

47. Ganesan AP, Clarke J, Wood O, et al. Tissue-resident memory features are linked to the magnitude of cytotoxic $\mathrm{T}$ cell responses in human lung cancer. Nat Immunol 2017;18:940-50.

48. Oezkan F, He K, Owen D, et al. OA13.07 Neoadjuvant Atezolizumab in Resectable NSCLC Patients: Immunophenotyping Results from the Interim Analysis of the Multicenter Trial LCMC3. J Thorac Oncol 2019;14:S242-S3.

49. Yarchoan M, Hopkins A, Jaffee EM. Tumor Mutational Burden and Response Rate to PD-1 Inhibition. N Engl J Med 2017;377:2500-1.

50. Alexandrov LB, Nik-Zainal S, Wedge DC, et al. Signatures of mutational processes in human cancer. Nature 2013;500:415-21.

51. Rizvi H, Sanchez-Vega F, La K, et al. Molecular Determinants of Response to Anti-Programmed Cell Death (PD)-1 and Anti-Programmed Death-Ligand 1 (PD-L1) Blockade in Patients With Non-Small-Cell Lung Cancer Profiled With Targeted Next-Generation Sequencing. J Clin Oncol 2018;36:633-41.

52. Carbone DP, Reck M, Paz-Ares L, et al. First-Line 
Nivolumab in Stage IV or Recurrent Non-Small-Cell

Lung Cancer. N Engl J Med 2017;376:2415-26.

53. Chiang AC, Herbst RS. Frontline immunotherapy for NSCLC - the tale of the tail. Nat Rev Clin Oncol 2020;17:73-4.

54. Joshi K, Chain BM, Peggs KS, et al. The "Achilles' Heel" of Cancer and Its Implications for the Development of Novel Immunotherapeutic Strategies. Cold Spring Harb Perspect Med 2018;8:a027086.

55. Jamal-Hanjani M, Quezada SA, Larkin J, et al. Translational implications of tumor heterogeneity. Clin Cancer Res 2015;21:1258-66.

56. Schumacher TN, Schreiber RD. Neoantigens in cancer immunotherapy. Science 2015;348:69-74.

57. Ward JP, Gubin MM, Schreiber RD. The Role of Neoantigens in Naturally Occurring and Therapeutically Induced Immune Responses to Cancer. Adv Immunol 2016;130:25-74.

58. Schumacher TN, Scheper W, Kvistborg P. Cancer Neoantigens. Annu Rev Immunol 2019;37:173-200.

59. Anagnostou V, Smith KN, Forde PM, et al. Evolution of Neoantigen Landscape during Immune Checkpoint Blockade in Non-Small Cell Lung Cancer. Cancer Discov 2017;7:264-76.

60. Reuben A, Gittelman R, Gao J, et al. TCR Repertoire Intratumor Heterogeneity in Localized Lung Adenocarcinomas: An Association with Predicted Neoantigen Heterogeneity and Postsurgical Recurrence. Cancer Discov 2017;7:1088-97.

61. Zhang J, Ji Z, Caushi JX, et al. Compartmental Analysis of T-cell Clonal Dynamics as a Function of Pathologic Response to Neoadjuvant PD-1 Blockade in Resectable Non-Small Cell Lung Cancer. Clin Cancer Res 2020;26:1327-37.

62. Dieu-Nosjean MC, Goc J, Giraldo NA, et al. Tertiary lymphoid structures in cancer and beyond. Trends Immunol 2014;35:571-80.

63. Stankovic B, Bjorhovde HAK, Skarshaug R, et al. Immune Cell Composition in Human Non-small Cell Lung Cancer. Front Immunol 2019;9:3101.

64. Kurebayashi Y, Emoto K, Hayashi Y, et al. Comprehensive Immune Profiling of Lung Adenocarcinomas Reveals Four Immunosubtypes with Plasma Cell Subtype a Negative Indicator. Cancer Immunol Res 2016;4:234-47.

65. Banat GA, Tretyn A, Pullamsetti SS, et al. Immune and Inflammatory Cell Composition of Human Lung Cancer Stroma. PLoS One 2015;10:e0139073.

66. Fridman WH, Pages F, Sautes-Fridman C, et al. The immune contexture in human tumours: impact on clinical outcome. Nat Rev Cancer 2012;12:298-306.

67. Germain C, Gnjatic S, Tamzalit F, et al. Presence of B cells in tertiary lymphoid structures is associated with a protective immunity in patients with lung cancer. Am J Respir Crit Care Med 2014;189:832-44.

68. Lund FE. Cytokine-producing B lymphocyteskey regulators of immunity. Curr Opin Immunol 2008;20:332-8.

69. Wang SS, Liu W, Ly D, et al. Tumor-infiltrating B cells: their role and application in anti-tumor immunity in lung cancer. Cell Mol Immunol 2019;16:6-18.

70. Bruno TC, Ebner PJ, Moore BL, et al. Antigen-Presenting Intratumoral B Cells Affect CD4(+) TIL Phenotypes in Non-Small Cell Lung Cancer Patients. Cancer Immunol Res 2017;5:898-907.

71. Bruno TC. New predictors for immunotherapy responses sharpen our view of the tumour microenvironment. Nature 2020;577:474-6.

72. Helmink BA, Reddy SM, Gao J, et al. B cells and tertiary lymphoid structures promote immunotherapy response. Nature 2020;577:549-55.

73. Cabrita R, Lauss M, Sanna A, et al. Tertiary lymphoid structures improve immunotherapy and survival in melanoma. Nature 2020;577:561-5.

74. Petitprez F, de Reynies A, Keung EZ, et al. B cells are associated with survival and immunotherapy response in sarcoma. Nature 2020;577:556-60.

75. Reuben A, Zhang J, Lin HY, et al. T cell repertoire analysis of non-small cell lung cancer patients treated with neoadjuvant nivolumab alone or in combination with ipilimumab (NEOSTAR trial). J Clin Oncol 2019;37:abstr 8532.

76. Reuben A, Zhang J, Chiou SH, et al. Comprehensive T cell repertoire characterization of non-small cell lung cancer. Nat Commun 2020;11:603.

77. Han J, Duan J, Bai H, et al. TCR Repertoire Diversity of Peripheral PD-1(+)CD8(+) T Cells Predicts Clinical Outcomes after Immunotherapy in Patients with Non-Small Cell Lung Cancer. Cancer Immunol Res 2020;8:146-54.

78. Laza-Briviesca R, Cruz-Bermudez A, Casarrubios M, et al. P2.04-10 Biomarkers of Pathological Response on Neo-Adjuvant Chemo-Immunotherapy Treatment for Resectable Stage IIIA NSCLC Patients. J Thorac Oncol 2019;14:S711.

79. Jiang T, Bai Y, Zhou F, et al. Clinical value of neutrophilto-lymphocyte ratio in patients with non-small-cell lung 
cancer treated with PD-1/PD-L1 inhibitors. Lung Cancer 2019;130:76-83.

80. Jiang T, Qiao M, Zhao C, et al. Pretreatment neutrophil-to-lymphocyte ratio is associated with outcome of advanced-stage cancer patients treated with immunotherapy: a meta-analysis. Cancer Immunol Immunother 2018;67:713-27.

81. Soyano AE, Dholaria B, Marin-Acevedo JA, et al. Peripheral blood biomarkers correlate with outcomes in advanced non-small cell lung Cancer patients treated with anti-PD-1 antibodies. J Immunother Cancer 2018;6:129.

82. Ren F, Zhao T, Liu B, et al. Neutrophil-lymphocyte ratio (NLR) predicted prognosis for advanced nonsmall-cell lung cancer (NSCLC) patients who received immune checkpoint blockade (ICB). Onco Targets Ther 2019;12:4235-44.

83. Kargl J, Busch SE, Yang GH, et al. Neutrophils dominate the immune cell composition in non-small cell lung cancer. Nat Commun 2017;8:14381.

84. Singel KL, Segal BH. Neutrophils in the tumor microenvironment: trying to heal the wound that cannot heal. Immunol Rev 2016;273:329-43.

85. Jablonska J, Lang S, Sionov RV, et al. The regulation of pre-metastatic niche formation by neutrophils. Oncotarget 2017;8:112132-44.

86. Mitchell KG, Diao L, Karpinets T, et al. Neutrophil expansion defines an immunoinhibitory peripheral and intratumoral inflammatory milieu in resected non-small cell lung cancer: a descriptive analysis of a prospectively immunoprofiled cohort. J Immunother Cancer 2020;8:e000405.

87. Eruslanov EB, Bhojnagarwala PS, Quatromoni JG, et al. Tumor-associated neutrophils stimulate $\mathrm{T}$ cell responses in early-stage human lung cancer. J Clin Invest 2014;124:5466-80.

88. Mishalian I, Bayuh R, Levy L, et al. Tumor-associated neutrophils (TAN) develop pro-tumorigenic properties during tumor progression. Cancer Immunol Immunother 2013;62:1745-56.

89. Anker P, Mulcahy H, Chen XQ, et al. Detection of circulating tumour DNA in the blood (plasma/serum) of cancer patients. Cancer Metastasis Rev 1999;18:65-73.

90. Gandara DR, Paul SM, Kowanetz M, et al. Bloodbased tumor mutational burden as a predictor of clinical benefit in non-small-cell lung cancer patients treated with atezolizumab. Nat Med 2018;24:1441-8.

91. Lam VK, Zhang J. Blood-based tumor mutation burden: continued progress toward personalizing immunotherapy in non-small cell lung cancer. J Thorac Dis 2019;11:2208-11.

92. Goldberg SB, Narayan A, Kole AJ, et al. Early Assessment of Lung Cancer Immunotherapy Response via Circulating Tumor DNA. Clin Cancer Res 2018;24:1872-80.

93. Wang Z, Duan J, Cai S, et al. Assessment of Blood Tumor Mutational Burden as a Potential Biomarker for Immunotherapy in Patients With Non-Small Cell Lung Cancer With Use of a Next-Generation Sequencing Cancer Gene Panel. JAMA Oncol 2019;5:696-702.

94. Abbosh C, Birkbak NJ, Wilson GA, et al. Phylogenetic ctDNA analysis depicts early-stage lung cancer evolution. Nature 2017;545:446-51.

95. Phallen J, Leal A, Woodward BD, et al. Early Noninvasive Detection of Response to Targeted Therapy in Non-Small Cell Lung Cancer. Cancer Res 2019;79:1204-13.

96. Giroux Leprieur E, Herbretau G, Dumenil C, et al. Circulating tumor DNA evaluated by Next-Generation Sequencing is predictive of tumor response and prolonged clinical benefit with nivolumab in advanced non-small cell lung cancer. Oncoimmunology 2018;7:e1424675.

97. Lam V, Tran H, Vasquez M, et al. MA23.02 Circulating Tumor DNA Analysis with a Novel Variant Classifier for Recurrence Detection in Resected, Early-Stage Lung Cancer. J Thorac Oncol 2018;13:S438.

98. Anagnostou V, Forde PM, White JR, et al. Dynamics of Tumor and Immune Responses during Immune Checkpoint Blockade in Non-Small Cell Lung Cancer. Cancer Res 2019;79:1214-25.

99. Zitvogel L, Ma Y, Raoult D, et al. The microbiome in cancer immunotherapy: Diagnostic tools and therapeutic strategies. Science 2018;359:1366-70.

100. Gopalakrishnan V, Helmink BA, Spencer CN, et al. The Influence of the Gut Microbiome on Cancer, Immunity, and Cancer Immunotherapy. Cancer Cell 2018;33:570-80.

101. Rooks MG, Garrett WS. Gut microbiota, metabolites and host immunity. Nat Rev Immunol 2016;16:341-52.

102. Sivan A, Corrales L, Hubert N, et al. Commensal Bifidobacterium promotes antitumor immunity and facilitates anti-PD-L1 efficacy. Science 2015;350:1084-9.

103. Vetizou M, Pitt JM, Daillere R, et al. Anticancer immunotherapy by CTLA-4 blockade relies on the gut microbiota. Science 2015;350:1079-84.

104. Matson V, Fessler J, Bao R, et al. The commensal microbiome is associated with anti-PD-1 efficacy in metastatic melanoma patients. Science 2018;359:104-8.

105. Routy B, Le Chatelier E, Derosa L, et al. Gut microbiome influences efficacy of PD-1-based immunotherapy against 
epithelial tumors. Science 2018;359:91-7.

106.Jin Y, Dong H, Xia L, et al. The Diversity of Gut

Microbiome is Associated With Favorable Responses to

Anti-Programmed Death 1 Immunotherapy in Chinese

Patients With NSCLC. J Thorac Oncol 2019;14:1378-89.
107. Travis WD, Dacic S, Wistuba I, et al. IASLC

Multidisciplinary Recommendations for Pathologic

Assessment of Lung Cancer Resection Specimens After

Neoadjuvant Therapy. J Thorac Oncol 2020;15:709-40.

Cite this article as: Pradhan M, Chocry M, Gibbons DL, Sepesi B, Cascone T. Emerging biomarkers for neoadjuvant immune checkpoint inhibitors in operable non-small cell lung cancer. Transl Lung Cancer Res 2021;10(1):590-606. doi: 10.21037/tlcr20-573 